\title{
CFH Y402H and ARMS2 A69S Genes Polymorphism Role in Susceptibility to Rhegmatogenous Retinal Detachment and its Complications
}

\author{
Zahra Hassanpour Aydinlou \\ center of excellence for biodiversity \\ Helaleh Vaezi \\ center of excellence for biodiversity \\ Mortaza Bonyadi \\ center of excellence for biodiversity \\ Abbas Rafat \\ ophthalmic research center \\ Mohammad hossein Jabbrpoor bonyadi ( $\sim$ mhbonyadi@yahoo.com ) \\ Shahid Beheshti University of Medical Sciences School of Medicine \\ Masoud Soheilian \\ ophthalmic research center
}

\section{Research article}

Keywords: Rhegmatogenous retinal detachment (RRD), ARMS2 A69S, CFH Y402H.

Posted Date: March 10th, 2021

DOl: https://doi.org/10.21203/rs.3.rs-294151/v1

License: (c) (i) This work is licensed under a Creative Commons Attribution 4.0 International License. Read Full License 


\section{Abstract}

\section{Background:}

Rhegmatogenous retinal detachment (RRD) is the most common type of retinal detachment. Purpose of this study is to evaluate the possible association of ARMS2 A69S and CFH Y402H polymorphisms with RRD and its postoperative complications.

\section{Materials and Methods:}

Polymerase chain reaction for DNA replication followed by restriction fragment length polymorphism for enzyme digestion. RRD patients (102 cases) and healthy controls (150 individuals for ARMS2 and 94 individuals for CFH). The two polymorphisms were genotyped by Polymerase Chain Reaction (PCR) - Restriction Fragment Length Polymorphism (RFLP) in a case-control study of 102 RRD patients and 150 controls to evaluate the possible association of ARMS2 A69S and CFH Y402H polymorphism with RRD susceptibility.

\section{Results:}

The genotypes frequencies for ARMS2 A69S and CFH Y402H found to be significantly different between RRD and normal controls (ARMS2 A69S 42.1\%vs 32.7\%, OR =1.69, $\mathrm{p}<0.036$ for GT and, CFH Y $402 \mathrm{H} 10.8 \%$ vs $6.4 \%, \mathrm{OR}=4.17, \mathrm{p}=0.01$ for CC genotype and $67.6 \%$ vs $40.4 \%$, OR=4.13, $p<0.0001$ for CT genotype). The ARMS2 A69S GT genotype showed significant association with postoperative cystoid macular edema (CME) (OR=3.11, $\mathrm{P}=0.0039)$.

\section{Conclusions:}

ARMS2 A69S and CFH Y402H showed significant association with RRD. The ARMS2 A69S GT genotype was also associated with postoperative cystoid macular edema.

\section{Background}

Retinal detachment (RD) is one of the most common causes of blindness in which the neurosensory retina is separated from the underlying retinal pigment epithelium (RPE) causing accumulation of the fluid in this space. ${ }^{1,2}$ The primary common symptom of the RD is sudden visual loss. Retinal detachment makes the neurosensory retina deprived of nutrients and oxygen resulting in severe visual disruption. The retinal detachment has three main types; rhegmatogenous (RRD), tractional (TRD) and exudative (ERD). ${ }^{1}$ The annual incidence of RRD is $10-15$ cases per 100000 Individuals. ${ }^{3}$ RRD has the preliminary symptoms of light flashes and floaters. In this type of RD, formation of a break in the retina causes the egress of fluid from the vitreous cavity into the sub-retinal space, which separates retina from the underlying RPE layer. RRD incidence is higher among elderly patients ${ }^{4}$ and this disease is observed with more frequency among men. ${ }^{5}$ High myopia, lattice retinal degeneration, trauma, previous cataract surgery, inflammation and some heritable syndromes are known risk factors for RRD. ${ }^{6-7}$ Familial aggregation studies and evaluation of monogenic conditions associated with RRD have suggested involvement of genetic factors in its development. ${ }^{8-9}$ There is little information about the genes contributing in the development of the non-syndromic RRD and its post-operative complications. Several studies in animal models have shown active role of inflammatory agents in the detached retina. ${ }^{10-12}$ An animal model study has also shown up-regulation of genes involved in complement pathway in RD. ${ }^{13}$ This study reported early activation of complement components genes in the detached and peri-detached retina. Two genes involved in the activities of complement pathway are ARMS2 A69S (age-related macular susceptibility 2, probable activator of complement system) and CFH Y402H (complement factor $\mathrm{H}$ ) gene (major inhibitor of complement alternative pathway). Several studies have previously demonstrated significant associations of the ARMS2 A69S and CFHY402H coding variants with retinal diseases such as age- related macular degeneration. ${ }^{14-15} \mathrm{~A}$ local inflammatory reaction has been suggested as a major causative factor for 
reactive changes in the retina after detachment even in the non-detached retina. ${ }^{13}$ Our purpose is to evaluate the possible role of $\mathrm{CFH} \mathrm{Y402H} \mathrm{and} \mathrm{ARMS2} \mathrm{A69S} \mathrm{polymorphisms} \mathrm{in} \mathrm{RRD} \mathrm{and} \mathrm{its} \mathrm{related} \mathrm{post-operative} \mathrm{complication.}$

\section{Methods}

\section{Study population}

In this case-control study consisting of two groups of patients and controls, we assessed genetically the polymorphic region rs10490924 in ARMS2 gene including 102 RRD patients and 150 controls and the polymorphic region rs1061170 in CFH gene including 102 RRD patients and 94 controls. All participants in this study had been introduced by a retina subspecialist (MHJB) to the genetic center. RRD was diagnosed based on a definition of a full thickness break in the neurosensory retina with a surrounding area of sub-retinal fluid extending greater than 2 disc diameters. ${ }^{16}$ All other types of retinal detachment (exudative, tractional and combined) were excluded. RRD cases secondary complicated cataract surgery or giant retinal tear excluded. Participants with a cataract surgery within 2 years of the detachment diagnosis or with known syndromic disease were excluded. All RRD cases have fulfilled at least 12 months of postoperative follow-up period for evaluation of postoperative complications. The study was approved by ethics committee of Tabriz University of Medical Sciences and informed consent was signed by all participants. This research is based on the Helsinki Declaration principles. All patients underwent detailed regular ophthalmic examination and macular optical coherence tomography (OCT) was also performed 3 and 6 months after operation. We documented the type of retinal break, bi/unilateral involvement, high myopic retinal degeneration and postoperative complications including long standing SRF (Sub-retinal fluid) remaining more than 3 months after operation, ERM (epi-retinal membrane), PVR (proliferative vitreo-retinopathy), CME (cystic macular edema), redetachment, vitreous haziness and macular atrophy. Scleral buckling or 23 gauge parsplana deep vitrectomy surgery (with silicon oil or SF6 gas injection) performed based on surgeon decision for patients. Silicon oil removal is done 3 months after vitrectomy.

\section{Genotyping:}

To evaluate association between these genes and RRD or its post -operative complications, peripheral blood samples isolated from normal individuals and RRD patients. DNA was extracted using deoxyribonucleic acid (DNA) extraction standard protocol (saturated salt). Extracted DNA samples were amplified by using polymerase chain reaction (PCR) and the genotypes of individuals in A69S and $\mathrm{Y} 402 \mathrm{H}$ polymorphic positions were determined by PCR-RFLP (restriction fragment length polymorphism). Primer sequences of $\mathrm{CFH}$ has been reported previously. ${ }^{15}$ ARMS2 primers which we used are: F:5'ATACCCAGGACCGATGGTAAC3' and R:5'AGAGGAAGGCTGAATTGCCTA3'. The PCR reaction was initiated by an early denaturation at $95^{\circ} \mathrm{C}$ for 5 min about both of genes followed by 30 continued cycles of denaturation at $95^{\circ} \mathrm{C}$ for $30 \mathrm{~s}$, annealing at $58.1^{\circ} \mathrm{C}$ for ARMS2 gene(45 s) and $59.5^{\circ} \mathrm{C}$ for $\mathrm{CFH}$ gene(45 s), and extension at $72{ }^{\circ} \mathrm{Ct}$ for $45 \mathrm{~s}$. Fragments of $450 \mathrm{bp}$ for ARMS2 and of $179 \mathrm{bp}$ for CFH were amplified. Then Pvull and TSP509I (Tasl) enzymes were used respectively for restriction enzyme digestion of obtained products from ARMS2 and CFH genes. For enzyme digestion of the PCR products, specific enzyme buffer, enzyme and ddH2O were subjected at $37{ }^{\circ} \mathrm{C}$ overnight. The results of enzyme digestion for ARMS2 gene were separable on $1.5 \%$ agarose gel. Pvull enzyme digests when there is $\mathrm{G}$ allele (wiled allele) creating two fragments of 257 base pair (bp) and $193 \mathrm{bp}$. Therefore, a single fragment of TT genotype (450 bp) and three fragments of GT genotype (450,257and193bp) will be displayed on the agarose gel. We identified genotypes of obtained fragments of enzyme digestion for CFH gene on 10\% polyacrylamide gel electrophoresis. TSP509/ enzyme digests when there is T allele (wiled allele) which creates two fragments of $119 \mathrm{bp}$ and $60 \mathrm{bp}$. Therefore, a single fragment of CC genotype (179 bp) and three fragments of CT genotype (179,119 and $60 \mathrm{bp}$ ) will be displayed on the polyacrylamide gel. Ten numbers of PCR products were subjected to sanger sequencing which confirmed the obtained results of PCR-RFLP. 


\section{Statistical analysis:}

Statistical analysis was performed using SPSS software statistics 16. The OR (odds ratio) and $\mathrm{Cl}$ (confidence interval) were calculated for comparison. We applied t-test and Chi-Square test to assess the differences between groups. ChiSquare test used to assess the Hardy-Weinberg equilibrium (HWE). There was statistically significant difference between case and control when P-values $<0.05$.

\section{Results}

One hundred and two RRD patients and 150 normal individuals as control group were included in this study for ARMS2 A69S polymorphism evaluation. Ninety four control participants included for CFH Y402H polymorphism evaluation. Baseline features of study groups has been summarized at Table 1. Case and control groups are matched regarding sex distribution and lens status. Mean age in RRD patients was significantly lower than controls (52.6 \pm 13.6 years vs. $72.2 \pm$ 6.3 years). Genotypes in control and RRD groups were consistent with Hardy-Weinberg equilibrium except CFH genotypes in RRD group (data not shown). Scleral buckling surgery performed for 34 cases and vitrectomy surgery performed for 68 cases. We have 11 patients with bilateral involvement. Studied genotypes were not associated with bilateral involvement. We have 68 cases with horse shoe tear related RRD and 34 cases with atrophic hole/lattice degeneration. None of the studied genotypes were associated with type of retinal break. We have 6 cases of redetachment during follow-up period. We performed reoperation for them and all remained attached during follow-up period.

Table 1

Baseline features, Characteristics of the Study Population

\begin{tabular}{|lllll|}
\hline & & Control & RRD & P value \\
\hline Age & Mean \pm SD & $72.2 \pm 6.3$ & $52.6 \pm 13.6$ & $<0.001^{\dagger}$ \\
\hline Sex & Male & 92 & 66 & $0.18^{*}$ \\
\hline Lens status & Female & 66 & 36 & \\
& Phakic & 81 & 54 & $0.44^{*}$ \\
\hline Pseudophakic & & & \\
\hline * Based on t-test. & 77 & 48 & \\
\hline * Based on Chi-Square test. & & & \\
\hline
\end{tabular}

The genotypes frequencies for ARMS2 A69S and CFH Y402H found to be significantly different between RRD and normal controls (ARMS2 A69S 42.1\% vs 32.7\%, OR = 1.69, $p<0.036$ for GT and, CFH Y402H 10.8\% vs 6.4\%, OR $=4.17, p=0.01$ for $\mathrm{CC}$ genotype and $67.6 \%$ vs $40.4 \%, \mathrm{OR}=4.13, \mathrm{p}<0.0001$ for CT genotype). ARMS2 A69S and CFH Y402H risk alleles were also significantly associated with $R R D$. $(O R=1.64 P=0.009$ and $O R=2.22, P<0.0001$, respectively, Table 2) 
Table 2

CFH Y402H, ARMS2 A69S Genotype and allelic distribution among RRD patients and control group

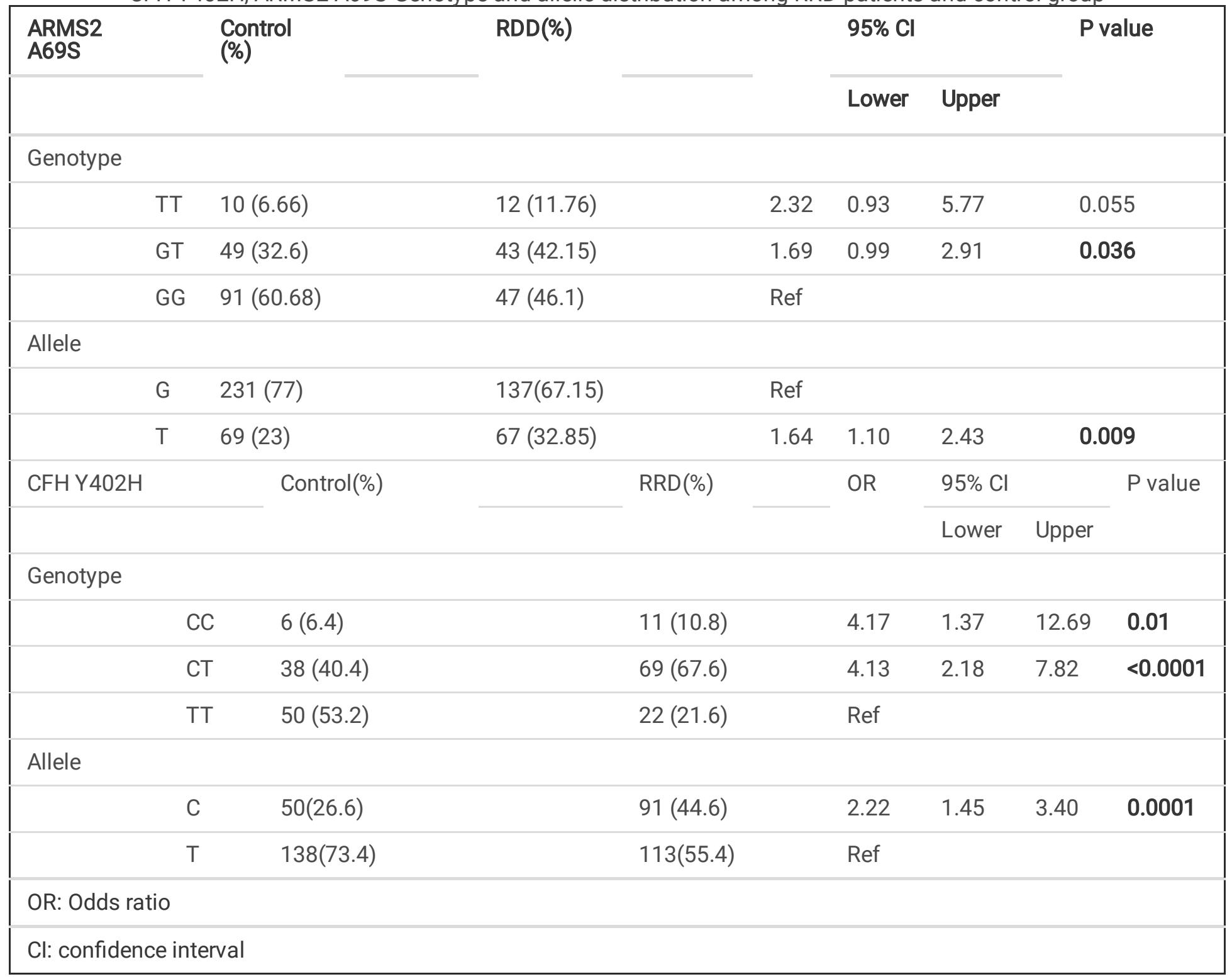

Seventeen of our RRD patients had CME postoperatively. The ARMS2 A69S GT genotype showed significant association with postoperative cystoid macular edema $(C M E)$. $(O R=3.11, P=0.039)$. These two genetic loci were not associated postoperative complications such as macular atrophy, redetachment, high grade PVR or persistent SRF.

\section{Discussion}

Our findings show that ARMS2 A69S and $\mathrm{CFH} \mathrm{Y402H} \mathrm{risk} \mathrm{variants} \mathrm{are} \mathrm{significantly} \mathrm{associated} \mathrm{with} \mathrm{RRD.} \mathrm{We} \mathrm{also} \mathrm{found}$ that ARMS2 A69S GT genotype has significant association with postoperative cystoid macular edema. RRD is a major cause of visual impairment and may be the result of the presence of retinal holes or tears. Although the only effective treatment modality of this disease is surgery, even successful operation fails to restore the normal visual capabilities because of functional alterations in the retina. Multiple inflammatory pathways have been shown to be activated after retinal detachment. ${ }^{17-18}$ Another study has shown early activation of inflammatory genes such as complement components genes in retinal detachment. ${ }^{13}$ This genetic expression alterations was also observed in the non-detached retina as well as in the underlying RPE layer. ${ }^{13}$

In this study we selected ARMS2 A69S and CFH Y402H as inflammatory polymorphic genetic loci to study their possible role in RRD susceptibility and its post-operative complication. ARMS2 (age-related maculopathy susceptibility) locus, 
originally named LOC387715, is located on Chromosome 10q26. Some have demonstrated a mitochondrial association of the ARMS2 protein and defined its retinal localization to the ellipsoid region of the photoreceptors. ${ }^{19}$ Others have reported its localization in the cytosol or extracellular matrix. ${ }^{20-21}$

ARMS2's role in the pro-inflammatory pathway has been shown by some authors. ${ }^{14,22-23}$ CFH Y402H (rs1061170) is located on Chromosome 1q32. Its polymorphism results in $\mathrm{T}$ to $\mathrm{C}$ change in exon 9 which causes tyrosine $(\mathrm{Y})$ to histidine $(\mathrm{H})$ exchange at position 402. CFH has an inhibitory effect on the alternative complement cascade and its polymorphism causes complement activation. The $\mathrm{CFH} \mathrm{Y402H} \mathrm{polymorphism} \mathrm{has} \mathrm{been} \mathrm{shown} \mathrm{to} \mathrm{increase} \mathrm{the} \mathrm{inflammatory} \mathrm{milieu} \mathrm{in} \mathrm{the}$ $\mathrm{RPE} /$ sub-retinal space. ${ }^{24-25}$ It has been suggested that ARMS2 and CFH Y402H genes have common pathway of effect because of synergistic interaction in AMD pathogenesis. ${ }^{14}$

In this study we found that among post-surgical RRD complications, cystoid macular edema is associated with ARMS2 A69S risk genotype. We could not find association of other complications such as macular atrophy, macular hole, redetachment, macular pucker, PVR or persistent SRF with studied genotypes. We observed strong association of ARMS2 A69S and CFH Y402H risk variants with RRD susceptibility. Apart from chronic RRD cases associated with atrophic holes, RRD is an acute disease which is dependent on fluid current through retinal break. We could not find any difference between RRD cases with HST and RRD cases with atrophic holes regarding these genetic loci polymorphisms. We speculate that these two genetic loci could have role in retinal break formation or their role in retinal/subretinal inflammatory milieu could affect neurosensory retinal attachment to RPE layer. In conclusion, this study showed strong association of ARMS2 A69S and CFH Y402H risk variants with RRD incidence and cystoid macular edema as its postoperative complication. We could not find any association between these genetic loci and other complications such as macular atrophy, macular hole, redetachment, macular pucker, PVR or persistent SRF. Limited number of cases and relatively short period of post- surgery follow-up are main limitation of this study. Future studies especially among RRD cases of chronic nature could clearly explain these genetic loci role in susceptibility to RRD and its complications.

\section{Declarations}

\section{Ethics approval and consent to participate}

This research is based on the Helsinki Declaration principles and is approved by ethics committee of Tabriz University of Medical Sciences.

\section{Consent for Publication}

Informed consent was signed by all authors.

\section{Availability of data and material}

Corresponding author has full access to data if necessary.

\section{Competing interests}

There is no competing interest to be declared.

\section{Funding}

The study funded by Center of Excellence for Biodiversity.

\section{Author contribution:}

Study design: MB, MHJB MS. 
Patients exam and enrollment : MHJB

Data analysis: ZHA, HV, AR.

Drafting: ZHA, HV, AR

\section{Acknowledgements}

We appreciate all patients who have been participated in this study.

\section{References}

1. - Ghazi NG, Green WR. Pathology and pathogenesis of retinal detachment. Eye (Lond). 2002;16(4):411-21.

2. - Delyfer MN, Raffelsberger W, Mercier D, Korobelnik JF, Gaudric A, Charteris DG, et al. Transcriptomic analysis of human retinal detachment reveals both inflammatory response and photoreceptor death. PLoS One. 2011;6(12):e28791.

3. - Royal College of Ophthalmologists. Management of Retinal Detachment. 2010.

4. - Wong TY, Tielsch JM, Schein OD. Racial difference in the incidence of retinal detachment in Singapore. Arch Ophthalmol. 1999;117:379-83.

5. - Mowatt L, Adrien G, Price N. Ethnic differences in the demand incidence of retinal detachments in two districts in the West Midlands. Eye. 2003;17:63-70.

6. - Higuchi Y, Hasegawa K, Yamashita M, Tanaka H, Tsukahara H. A novel mutation in the COL2A1 gene in a patient with Stickler syndrome type 1: a case report and review of the literature. J Med Case Rep. 2017;26(1):237. 11(.

7. - Johnston T, Chandra A, Hewitt AW. Current Understanding of the Genetic Architecture of Rhegmatogenous Retinal Detachment. Ophthalmic Genet. 2016;37(2):121-9.

8. - Go SL, Hoyng CB, Klaver CC. Genetic risk of rhegmatogenous retinal detachment: a familial aggregation study. Arch Ophthalmol. 2005;123(9):1237-41.

9. - Mitry D, Williams L, Charteris DG, Fleck BW, Wright AF, Campbell H. Population-based estimate of the sibling recurrence risk ratio for rhegmatogenous retinal detachment. Invest Ophthalmol Vis Sci. 2011 Apr;20(5):2551-5. 52(.

10. - Lewis GP, Sethi CS, Carter KM, Charteris DG, Fisher SK. Microglial cell activation following retinal detachment: a comparison between species. Mol Vis. 2005;11:491-500.

11. - Wurm A, Pannicke T, landiev I, Bühner E, Pietsch UC, Reichenbach A, et al. Changes in membrane conductance play a pathogenic role in osmotic glial cell swelling in detached retinas. Am J Pathol. 2006;169(6):1990-8.

12. - landiev I, Uckermann O, Pannicke T, Wurm A, Tenckhoff S, Pietsch UC, et al. Glial cell reactivity in a porcine model of retinal detachment. Invest Ophthalmol Vis Sci. 2006;47(5):2161-71.

13. - Hollborn M, Francke M, landiev I, Bühner E, Foja C, Kohen L, et al. Early activation of inflammation- and immune response-related genes after experimental detachment of the porcine retina. Invest Ophthalmol Vis Sci.

2008;49(3):1262-73.

14. - Jabbarpoor Bonyadi MH, Yaseri M, Bonyadi M, Soheilian M, Karimi S. Association of Combined Complement Factor H Y402H and ARMS/LOC387715 A69S Polymorphisms with Age-related Macular Degeneration: A Meta-analysis. Curr Eye Res. 2016;41(12):1519-25.

15. - Bonyadi M, Foruzandeh Z, Mohammadian T, Fotouhi N, Soheilian M, Jabbarpoor Bonyadi MH, et al. Evaluation of CCcytokine ligand 2 and complementary factor $\mathrm{H} Y 402 \mathrm{H}$ polymorphisms and their interactional association with agerelated macular degeneration. Acta Ophthalmol. 2016;94(8):e779-85.

16. - Polkinghorne PJ, Craig JP. Northern New Zealand Rhegmatogenous Retinal Detachment Study: epidemiology and risk factors. Clin Exp Ophthalmol. 2004;32:159-63. 
17. - Lewis GP, Sethi CS, Carter KM, Charteris DG, Fisher SK. Microglial cell activation following retinal detachment: a comparison between species. Mol Vis. 2005;11:491-500.

18. - Nakazawa T, Matsubara A, Noda K, Hisatomi T, She H, Skondra D, et al. Characterization of cytokine responses to retinal detachment in rats. Mol Vis. 2006;12:867-78.

19. - Fritsche LG, Loenhardt T, Janssen A, Fisher SA, Rivera A, Keilhauer CN, et al. Age-related macular degeneration is associated with an unstable ARMS2 (LOC387715) mRNA. Nat Genet. 2008;40(7):892-6.

20. - Kortvely E, Hauck SM, Duetsch G, Gloeckner CJ, Kremmer E, Alge-Priglinger CS, et al. ARMS2 is a constituent of the extracellular matrix providing a link between familial and sporadic age-related macular degenerations. Investigative Ophthalmology Visual Science. 2010;51(1):79-88.

21. - Wang G, Spencer KL, Court BL, Olson LM, Scott WK, Haines JL, et al. Localization of age-related macular degeneration-associated ARMS2 in cytosol, not mitochondria. Investig Ophthalmol Vis Sci. 2009;50(7):3084-90.

22. - Reynolds R, Hartnett ME, Atkinson JP, Giclas PC, Rosner B, Seddon JM. Plasma complement components and activation fragments: associations with age-related macular degeneration genotypes and phenotypes. Investig Ophthalmol Vis Sci. 2009;50(12):5818-27.

23. - Smailhodzic D, Klaver CCW, Klevering BJ, Boon CJ, Groenewoud JM, Kirchhof B, et al. Risk alleles in CFH and ARMS2 are independently associated with systemic complement activation in age-related macular degeneration. Ophthalmology. 2012;119(2):339-46.

24. - Clark SJ, Perveen R, Hakobyan S, Morgan BP, Sim RB, Bishop PN, et al. Impaired binding of the AMD associated complement factor $\mathrm{H} 402 \mathrm{H}$ allotype to Bruch's membrane in human retina. Journal of Biological Chemistry. 2010; (285):30192-30202.

25. - Clark SJ, Ridge LA, Herbert AP, Hakobyan S, Mulloy B, Lennon R, et al. Tissue-specific host recognition by complement factor $\mathrm{H}$ is mediated by differential activities of its glycosaminoglycan-binding regions. The Journal of Immunology. 2013;(190):2049-2057. 